\title{
Usability Audit Technology of Travel Agency Website
}

\author{
Ganna Bedradina, Sergii Nezdoyminov, Andrii Ivanov
}

\begin{abstract}
In the context of growing competition in the market of tourist services, it becomes necessary to introduce digital technologies: booking tours with the help of on-line service, which saves time, speeds up the processing of the application and confirmation of the selected tour. The introduction of information technologies in the system of booking and reservation of hotels, air tickets requires the development of high-quality design and convenient search for consumers on the websites of travel companies. In the modern conditions of globalization of the tourist market, quality management of website service has become a major factor in improving the competitiveness of tourism businesses. An important aspect of the activity of a tourist enterprise is the formation of tools for evaluating its own tourist site in comparison with the websites of enterprises-leaders of the tourism market. Due to the limited financial, labor and time resources objectively arises a problem of ranking directions, methods and specific measures to improve the service quality offered by travel agencies on their web pages. To further identify ways to improve the quality and profitability of the travel agency's website, the authors proposed to use modern methods of website usability audit, that is, the evaluation of the ease of use of the site by the end user. The authors conducted an audit of the websites of travel agencies basing on the methods of taxonomic analysis. They defined the main indicators of assessing the level of quality service provided to visitors of the site, which significantly affect the e-commerce system of travel agencies and the total profit from on-line sales of travel services. The method proposed by the authors can serve as a basis for further improvement of audit technologies of websites of travel agencies and e-commerce operations.
\end{abstract}

Keywords: usability audit technologies, website, benchmarking, taxonomic analysis methods, travel agencies.

\section{INTRODUCTION}

In the context of international integration and globalization of the tourist market, the introduction of digital technologies: booking tours using on-line service of the tour operator's website is becoming increasingly important.

Revised Manuscript Received on December 30, 2019.

* Correspondence Author

Ganna Bedradina, Senior Lecturer, Department of Tourism and Hotel and Restaurant Business, Odessa National Economics University, Odessa, Ukraine.

Sergii Nezdoyminov*, Assistant Professor, Department of Tourism and Hotel and Restaurant Business, Odessa National Economics University, Odessa, Ukraine.

Andrii Ivanov, Assistant Professor, Department of Tourism and Hotel and Restaurant Business, Odessa National Economics University, Odessa, Ukraine.

(C) The Authors. Published by Blue Eyes Intelligence Engineering and Sciences Publication (BEIESP). This is an open access article under the CC BY-NC-ND license (http://creativecommons.org/licenses/by-nc-nd/4.0/)
Competing with each other, companies are looking for new ways to meet the needs of tourists in quality service, while trying to optimally use the available technological and infrastructure resources. Therefore, it is important to improve the on-line service of travel agencies on the basis of audit of the websites of tourism industry enterprises. Tour operators, when evaluating their own website, first of all pay attention to the website design, color scheme, logo size and attractiveness, payment tools for services, but they do not analyze the usability of the site, that is, the ease of use of the site by the end user [1]. Nowadays, the main difficulty of promotion of services resides in the understanding of the strategic goal of the provider's website, that is, to provide the user with the necessary information or service that he is looking for on the Internet.

The purpose of the article is to develop audit tools aimed at improving the travel agencies' websites. The audit methodology is based on the hypothesis that the indicators that characterize its usability depend on the objective characteristics of the request of service consumers (conditions of service in travel agencies and hotels, conditions of food services and booking tickets), and on some values that are not directly observable and measurable (hobby interests of tourists, additional inclusive services, the attractiveness of recreational resources).

The researchers draw attention to the fact that the understanding of the specific needs of users' search allows to formulate the main usability audit criteria as for the assessment of technological quality of the website [2; 3; 4]. According to the opinions of scientists, some characteristics of the quality indicators of the content of the websites of travel agencies are latent indicators, it means that they are not directly measurable and can described by a variety of so-called signs-symptoms [5; 6; 7]. Therefore, it is necessary to consider the content of latent characteristics of services and tools of the site as a set of properties and service processes that give it the ability to meet the needs of tourists on-line.

\section{MATERIALS AND METHODS}

The analysis of the scientific literature shows the unity of opinions of experts on the fact that the usability audit of the website of a travel agency is a set of actions and activities aimed at identifying certain problems that create difficulties in the process of interaction with the web resource. During the usability audit, experts are involved to evaluate the web resource, conduct testing and form a list of comments and recommendations for improving the site [3]. 


\section{Usability Audit Technology of Travel Agency Website}

Usability audits are aimed at analyzing the functioning of all elements of the site, as well as the behavior of potential customers.

The proposed technology of usability audit based on benchmarking consists of the analysis of the user interface and user experience for further comparison with the reference travel agency website. In order to carry out usability audit of websites of travel agencies by the method of expert assessments, we selected 6 main criteria for evaluating travel websites:

- information content (amount of information provided, level of detail of the data, use of photo and video about services of the travel agency;

- navigation (whether information is well-structured, ease of use of the website);

- technical capabilities (availability of information guides, possibility of booking tours, excursions, air tickets, hotels);

- travel agency website design;

- loading speed of the site and its subsections;

- regularity of information updates.

Our approaches are based on the research of scientists who believe that marketing technologies are a key tool to test the effectiveness of e-commerce in the field of tourism services [8; 9; 10; 11]. In our opinion, it is expedient to use the method of taxonomic analysis as a part of the tools of audit of travel agencies on the basis of benchmarking. This method is characterized by the simplicity of the mathematical apparatus, the absence of any requirements for the set of objects under study, the convenient scale of the estimates that facilitate the analysis and ranking of objects. The key indicator of this method is the taxonomic index of the level of development of the website, which is a synthetic value, "resultant force" of all indicators-signs that characterize the objects of the studied assembly. The taxonomic index serves as the basis for the linear ordering of the elements of this assembly. The process of constructing of a taxonomic index begins with the formation of elements of the observation matrix $(\mathrm{X})$ :

$$
X=\left(X_{i j}\right), i=1, \ldots, m ; j=1, \ldots, n \text {, }
$$

where $X_{i j}$ is the value of the $j^{\text {th }}$ indicator for the $i^{\text {th }}$ object, $m$ is the number of objects;

$n$ is the number of indicators-signs.

The indicators of the observation matrix are heterogeneous, because they describe different properties of objects, so it is necessary to standardize them in accordance with the formula:

$$
\begin{gathered}
Z_{i j}=\frac{X_{i j}-\bar{X}_{j}}{S_{j}}, \\
\text { where, } \\
\bar{X}_{j}=\frac{\sum X_{i j}}{m}
\end{gathered}
$$

$$
S_{j}=\sqrt{\frac{\sum\left(X_{i j}-\bar{X}_{j}\right)^{2}}{m}},
$$

where $\bar{X}_{j}$ is the arithmetic mean value of the $j^{\text {th }}$ attribute; $\mathrm{S}_{j}$ is the standard deviation of the $j^{\text {th }}$ indicator;

$Z_{i j}$ is the standardized value of the $j^{\text {th }}$ indicator for the $i^{\text {th }}$ object.

In taxonomic analysis, all signs are divided into stimulators and destimulators. Stimulators include the signs positively influencing the level of objects development, and destimulators are the signs that have negative impact. The division of signs into stimulators and destimulators serves as the basis for the creation of the so-called standard development (of the reference object), which is the point $\mathrm{P}_{\mathrm{o}}$ with coordinates $\mathrm{Z}_{01}, \mathrm{Z}_{02}, \ldots, \mathrm{Z}_{0 \mathrm{n}}$ :,

$$
\begin{aligned}
& Z_{o j}=\max Z_{i j}, \text { if } j \in K \\
& Z_{o j}=\min Z_{i j}, \text { if } j \notin K
\end{aligned}
$$

where $K$ is the set of stimulators of the $j^{\text {th }}$ sign for the $i^{\text {th }}$ object.

One of the fundamental concepts of multivariate analysis is the distance between objects in the multidimensional space. In taxonomic analysis, Euclidean distance is most often used, which best corresponds to intuitive ideas of the proximity of objects in three-dimensional space. In addition, the Euclidean distance successfully fits its mathematical form in the traditional statistical indicators such as standard deviation and variance. The distance $\mathrm{C}_{i o}$ between individual objects and the development standard (reference object) $R_{0}$ using the Euclidean distance is calculated by the formula:

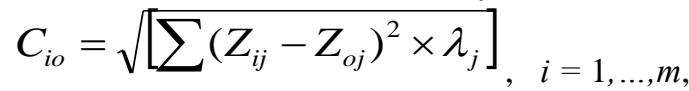

where $\lambda_{j}$ is the weighting factor for the $j^{\text {th }}$ indicator.

Weighting factors $\lambda_{j}$ reflect the degree of importance of each $j^{\text {th }}$ indicator. Their values range from 0 to 1 . The sum of the weighting factors must be equal to 1 . In the theory of multivariate analysis, there are various ways of determining weighting factors. In practice, the latter are more often determined on the basis of expert assessments. The obtained distances serve as initial values that are used in determining the taxonomic index of the object development level $\left(\mu_{i}\right)$, which characterizes the degree of its similarity to the standard. This calculation is performed in the following sequence:

$$
\begin{aligned}
& \text { - arithmetic average distance from the standard } \\
& \bar{C}_{o}=\frac{\sum \bar{C}_{i o}}{m} \text { object }\left(\bar{C}_{o}\right) \text { : } \\
& \quad \text { - standard deviation of distances from the } \\
& S=\sqrt{\frac{\sum\left(C_{i o}-\bar{C}_{o}\right)^{2}}{m}},
\end{aligned}
$$

- taxonomic index of the development level of the $i^{\text {th }}$ object $\left(\mu_{i}\right)$ :,

$\mu_{i}=1-\frac{C_{i o}}{\bar{C}_{o}+2 S}$,

The higher the value of the taxonomic index for the $i^{\text {th }}$ object, the higher the measure of its similarity to the standard is and, accordingly, the higher the level of development is. In addition to the classical algorithm discussed above (7-10), a modified algorithm is also distinguished in the modern theory of taxonomic analysis [12]. The taxonomic index calculated on its basis, in contrast to the classical algorithm, reflects the measure of remoteness of each object from the anti-standard object, which has reached the lowest level of development.

Published By: 
At the initial stage of the analysis procedure, based on the use of a modified algorithm, all signs that are destimulators turn into stimulators according to the formula:

$X_{i j}=1 / X_{i j}^{\prime}$

where $X_{i j}^{\prime}$ is the initial value of the characteristic of the sign-destimulator.

When using the modified algorithm, the value of the taxonomic index for each $i^{\text {th }}$ object $\left(\mu_{i}\right)$ is calculated by the following formula:

$\mu_{i}=\frac{C_{i o}}{\bar{C}_{o}+2 S}$

\section{RESULT AND DISCUSSION}

Usability audit of websites was carried out on the example of tourist agencies of Odessa region. Ten tourism enterprises of different organizational and legal forms and scopes of activities with different market segments and different rates of development were selected for experimental studies. It should be noted that the differences in the methods of calculating the taxonomic index inherent to the classical and modified algorithms, as a rule, cause differences in the values of the obtained estimates. The classical algorithm determines more precisely the points of objects-leaders, a modified algorithm - of objects-outsiders.

On the basis of the proposed methodology, we will audit the websites of ten travel companies. According to the results of the expert assessment, the enterprise "01" was identified as a leader among the studied travel agencies. To compare the results of the analysis of the websites of ten travel companies, the tourism enterprise " 04 " was chosen as the main object of the study.

Table I shows the primary values of the audit indicators of websites in travel agencies and their weighting factors determined by experts. The factors-stimulators include indicators 1-2, 4-6 (table. I.) The third indicator that is the technical capabilities of the site (time spent on booking a tour) should be attributed to destimulators. Results of the standardization of the estimates made on the basis of formulas (2-4), the results of the calculation of the distance to the reference object, values of taxonomic index and ranking was calculated on the basis of modified algorithm shown in table II-IV.

Table I: Primary values of audit indicators of travel agencies' website

\begin{tabular}{|c|c|c|c|c|c|c|}
\hline \multirow[b]{2}{*}{ 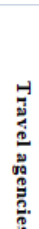 } & \multicolumn{6}{|c|}{ Indicators } \\
\hline & 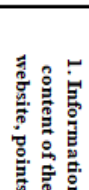 & 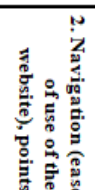 & 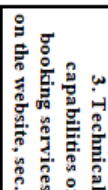 & 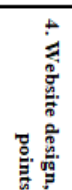 & 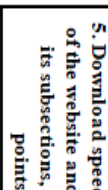 & 要 \\
\hline 1 & 1.5941 & 1.3781 & -1.6481 & 0.4743 & 1.9873 & 1.9261 \\
\hline 2 & 0.2657 & 0.0656 & 0.8874 & -0.3162 & 0.3846 & 0.4445 \\
\hline 3 & 0.9299 & 0.7218 & -1.0142 & 1.2649 & 0.7052 & 0.9383 \\
\hline 4 & -0.3985 & 0.0656 & 0.2535 & 0.4743 & 0.0641 & -0.5433 \\
\hline 5 & -1.0627 & -0.5906 & 0.2535 & -1.1068 & -1.218 & -0.0494 \\
\hline 6 & -0.3985 & -1.2468 & 1.5213 & -1.8974 & -1.5385 & -1.0371 \\
\hline 7 & -1.7269 & -1.903 & -0.3803 & -0.3162 & -0.577 & -1.531 \\
\hline 8 & 0.9299 & 0.7218 & -1.0142 & 1.2649 & 0.3846 & 0.4445 \\
\hline 9 & 0.2657 & 0.0656 & 0.8874 & -0.3162 & -0.2564 & -0.5433 \\
\hline 10 & -0.3985 & 0.7218 & 0.2535 & 0.4743 & 0.0641 & -0.0494 \\
\hline
\end{tabular}

Table II: Standardized values of website usability audit indicators by classical taxonomic analysis algorithm

\begin{tabular}{|c|c|c|c|} 
[ravel agencie & $\begin{array}{c}\text { Distance to } \\
\text { the standard } \\
\left(\boldsymbol{C}^{\boldsymbol{K}}{ }_{i o}\right)\end{array}$ & $\begin{array}{c}\text { Taxonomic } \\
\text { index }\left(\boldsymbol{\mu}^{\mathbf{K}} \mathbf{}\right)\end{array}$ & $\begin{array}{c}\text { Website rank } \\
\left(\mathbf{R}^{\mathbf{K}}{ }\right)\end{array}$ \\
\hline 1 & 0.3062 & 0.9103 & 1 \\
\hline 2 & 1.6589 & 0.5141 & 5 \\
\hline 3 & 0.7876 & 0.7693 & 2 \\
\hline 4 & 1.8325 & 0.4633 & 6 \\
\hline 5 & 2.2503 & 0.3409 & 8 \\
\hline 6 & 2.9265 & 0.1428 & 10 \\
\hline 7 & 2.8383 & 0.1687 & 9 \\
\hline 8 & 1.0088 & 0.7045 & 3 \\
\hline 9 & 1.9935 & 0.4161 & 7 \\
\hline 10 & 1.5768 & 0.5381 & 4 \\
\hline
\end{tabular}

Table III: Results of the taxonomic analysis and ranks of the website performed on the basis of the classical algorithm

\begin{tabular}{|c|c|c|c|}
\hline $\begin{array}{c}\text { Travel } \\
\text { agencies }\end{array}$ & $\begin{array}{c}\begin{array}{c}\text { Distance } \\
\text { from }\end{array} \\
\text { the } \\
\text { anti-standard } \\
\left(C^{\left.u_{i o}\right)}\right. \\
\end{array}$ & $\begin{array}{l}\text { Taxonomic } \\
\text { index }\left(\mu^{\mathrm{m}}{ }_{\mathrm{i}}\right)\end{array}$ & $\begin{array}{l}\text { Website } \\
\operatorname{rank}\left(R^{\mu_{i}}\right)\end{array}$ \\
\hline 1 & 3.2204 & 0.949 & 1 \\
\hline 2 & 1.765 & 0.5201 & 5 \\
\hline 3 & 2.5952 & 0.7647 & 2 \\
\hline 4 & 1.6202 & 0.4774 & 6 \\
\hline 5 & 1.1237 & 0.3311 & 8 \\
\hline 6 & 0.5875 & 0.1731 & 10 \\
\hline 7 & 0.9108 & 0.2684 & 9 \\
\hline 8 & 2.4602 & 0.725 & 3 \\
\hline 9 & 1.4758 & 0.4349 & 7 \\
\hline 10 & 1.9193 & 0.5656 & 4 \\
\hline
\end{tabular}

Table IV: Results of the taxonomic analysis and ranks of the website performed on the basis of the modified algorithm

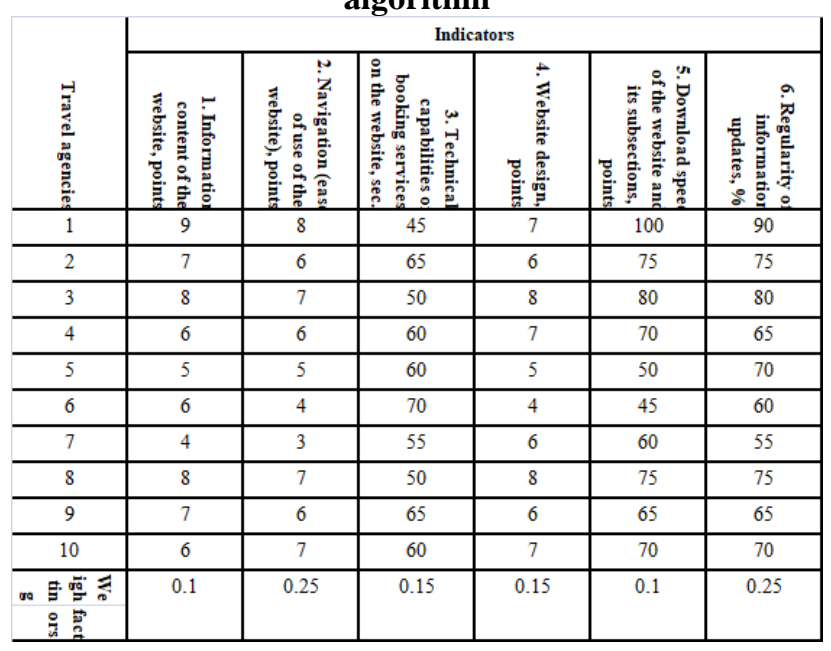




\section{Usability Audit Technology of Travel Agency Website}

Analyzing the data from the table IV, it can be concluded that the undisputed leader in the quality of the website is the company "01", which taxonomic index is only $5 \%$ behind the standard $\left(\mu^{\mathrm{M}_{\mathrm{i}}} 01=0.9490\right)$. There is also a significant gap between the three leaders and other tourism enterprises. The website of the company "4", which was chosen by experts for comparing with the leader, has the 6th rank. So, according to the results of the audit of websites, we can draw the conclusion that there are significant reserves in the management of the websites of travel agencies and improvement of on-line service in the company "04". This company is recommended to install Google Analytics Counter on its website, which allows to identify problems that users may face on the pages of the website, for example, when navigating the site or filling out a booking form for obtaining services. The results of our analysis support and complement the scientific approaches of researchers on usability audit, which is carried out in order to determine the current state, identify strengths and weaknesses of the agencies' websites $[4 ; 13 ; 14]$.

\section{CONCLUSION}

Usability audit of websites of the travel agencies showed that the method of the analysis offered by authors allows comparing the degree of introduction of modern technologies of Internet marketing on the websites of tourism enterprises. Results of the audit and ranking of the enterprises' websites on the basis of the taxonomy methodology applied to ten travel agencies confirm the hypothesis that the website has a high level of quality of on-line service if the degree of approximation of its quality model to a reference model has bigger value of taxonomic index. The presented tools of the travel agencies' website audit can complement modern audit technology of web resources of a service provider. According to the results of the calculation of distances to the reference object and ranking of the websites of the travel agencies some measures can be suggested to increase the conversion rate; reduce the price for attracting a new tourist; increase sales of travel services; reduce the cost of customer support; increase the frequency of consumer orders.

\section{REFERENCES}

1. ISO 25000 Standards, 2018. "Usability. (ISO/IEC)" Available: http://iso25000.com/index.php/en/iso-25000-standards/iso25010/61-u sability

2. Duggan, K. and Lang, J., "Six drivers for high-user satisfaction of tourism websites: Performance auditing of Maine, Massachusetts, and New York's direct marketing strategies", Woodside, A. (Ed.) Tourism-Marketing Performance Metrics and Usefulness Auditing of Destination Websites (Advances in Culture, Tourism and Hospitality Research, Vol. 4), 2010, Emerald Group Publishing Limited, Bingley, pp. 27-45. https://doi.org/10.1108/S1871-3173(2010)0000004007

3. Trinidad Domínguez Vila, Elisa Alén González \& Simon Darcy "Accessible tourism online resources: a Northern European perspective", Scandinavian Journal of Hospitality and Tourism, vol. 19 (2), 2019, pp. 140-156, DOI: 10.1080/15022250.2018.1478325

4. Rukshan A. "Usability themes in high and low context cultures: A comparative study". PhD thesis, 2019, Murdoch University. Available: https://researchrepository.murdoch.edu.au/id/eprint/45853/

5. Alegre J., Mateo S., Pou L., “A latent class approach to tourists' length of stay", Tourism Management, Vol. 3(32), 2011, pp. 555-563.

6. Yankovyi O. G., Latent signs in the economy: a monograph, Odessa: Atlanta, 2015, Odessa, pp. 65-75.

7. Bedradina, G., Nezdoyminov, S., "Measuring the Quality of the Tourism Product in the Tour Operator Business", Montenegrin Journal of Economics, 15(2), 2019. doi:10.14254/1800-5845/2019.15-2.7
8. Sudeshna Dutta, "Dimension specific technique of evaluating service quality", International Journal of Innovative Technology and Exploring Engineering (IJITEE), vol. 8(12), 2019. Available: https://www.ijitee.org/wp-content/uploads/papers/v8i12/L328910812 19.pdf

9. Rondović, B., Djuričković, T., \& Kašćelan, L. Drivers of E-business diffusion in tourism: a decision tree approach. Journal of theoretical and applied electronic commerce research, 14(1), 2019, pp. 30-50.

10. Shamma H. and Hassan S., "Customer-driven benchmarking", Benchmarking: An International Journal, vol. 20 (3), 2013, pp. 377-395. https://doi.org/10.1108/14635771311318144

11. Tien-Chin Wang, Huang Shu-Li, "Performance Measurement and Benchmarking of Large-Scale Tourist Hotels", International Journal of Business and Economics Research, vol. 7 (4), 2018, pp. 97-101. doi: 10.11648/j.ijber.20180704.13

12. Yehupov Y. A., "Improving the correctness of multidimensional estimates in the process of formation of the production program of the enterprise", Economic innovations: a collection of scientific works, vol. 38, 2009, pp. 68-80.

13. Król, K., "Forgotten agritourism: abandoned websites in the promotion of rural tourism in Poland", Journal of Hospitality and Tourism $\begin{array}{lllll}\text { Technology, } & \text { vol. } & 10 & \text { (3), } & \text { pp. }\end{array}$ https://doi.org/10.1108/JHTT-09-2018-0092

14. Shageetha Ramachandran, Rozi Nor Haizan Nor, Yusmadi Yah Jusoh, "Usability Assessment for the Enhancement of Quality of a Web Portal Interface" Available: https://www.ijeat.org/wp-content/uploads/ papers/v9i1/A2635109119.pdf

\section{AUTHORS PROFILE}

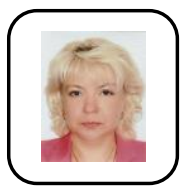

Ganna Bedradina, Ph.D. in Economics, senior lecturer of the Department of Tourism and Hotel and Restaurant Business of the Odessa National Economics University. The owner of the travel company-operator "Seleznev Tour", engaged in scientific activities since 2008. Author and co-author of more than 60 scientific and educational works on the problems of tourism and hotel and restaurant business.

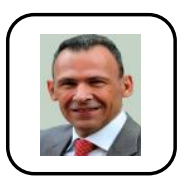

Sergii Nezdoyminov, Ph.D. in Economics, associate professor of the Department of Tourism and Hotel and Restaurant Business of the Odessa National Economics University. Professionally engaged in the economy and management of tourism since 1990. Author and co-author of more than 200 scientific and educational works on the problems of hospitality and tourism, published in Ukrainian and foreign publications.

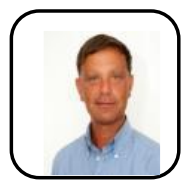

Andrii Ivanov, Ph.D. in Economics, associate professor of the Department of Tourism and Hotel and Restaurant Business of the Odessa National Economics University. Professionally engaged in the managemen and marketing of tourism since 2005. Author and co-author of more than 150 scientific and educational works on the problems of management and marketing of tourism. 